\title{
How Educational Developers Can Re-engage Mid-Career Faculty Using SoTL
}

\author{
Melanie Hamilton, Lethbridge College, and Nicola Simmons Brock University, \\ Canada
}

\begin{abstract}
Mid-career faculty (MCF) currently make up a significant number of faculty at higher educational institutions. This group comprises key stakeholders with institutional history, diverse teaching and learning experiences, and strong relationships with colleagues. While faculty need different kinds of support and opportunities at different career stages, it has been reported that mid-career professional development is under-researched and overlooked. We contend that professional development for MCF is essential if these faculty are going to continue to grow as educators, leaders, and scholars. With the support of Educational Developers (EDs), the Scholarship of Teaching and Learning (SoTL) is one way for faculty to focus their professional development in the middle years of their career. Drawing on the literature about challenges for MCF and using the micromeso-macro-mega framework, we explore ways in which EDs can use SoTL to reengage MCF on a revitalized path. Our synthesis offers reflections on our career experiences as EDs and boundary-spanning points to ponder for both EDs and MCF as they enter into SoTL engagement.
\end{abstract}

Keywords: SoTL, mid-career faculty, 4M framework, Educational Developers, professional development

CC-BY-NC-ND Licence 4.0 This is an Open Access article distributed under the terms of the Creative Commons - Attribution License 4.0 International (https://creativecommons.org/licenses/by/4.0/), which permits copy and redistribution with appropriate credit. This work cannot be used for commercial purposes and cannot be distributed if the original material is modified. 


\section{INTRODUCTION}

Baldwin et al. (2008) describe the mid-career period for faculty as the most lengthy, productive, and influential years in an academic career. Some faculty members, however, report that as they move through their mid-career period, they often feel stuck, less valued, exhausted, and unmotivated (Baker et al., 2019; Wilson, 2012). As this occurs, faculty may see their teaching and learning stagnate.

Mid-career faculty (MCF) generally comprise the largest group of all faculty both at colleges and universities (Karraa \& McCaslin, 2015; Pastore, 2013; Welch et al., 2019). Baldwin and Chang (2006) and Pastore (2013) argue that MCF are essential players as institutions adapt and change within the landscape of higher education. It is crucial, they say, to focus specific MCF development on topics such as updated knowledge and skills, technological advancements, aligning work with institutional strategic plans, and research/scholarship projects (Baldwin \& Chang, 2006; Baker, 2019). Unfortunately, mid-career issues are under-researched (GrantVallone \& Ensher, 2017), ignored (Baker, 2019), and overlooked (Weimer, 2009).

We have found that encouraging MCF to engage in the Scholarship of Teaching and Learning (SoTL) is one way to reinvigorate their careers and passion for teaching and learning. MCF have a unique opportunity to set new goals and focus their energy on areas of teaching and learning that are important to them (Baldwin \& Chang, 2006; Grant-Vallone \& Ensher, 2017; Pinter, 2019), moving from scholarly teaching to SoTL (Smith, 2017). This is an ideal career stage to engage with a SoTL project, which can also provide opportunities to connect with other MCF within and across disciplines at their home institution. At the same time, Hutchings et al. (2011) acknowledge that to transition from scholarly teaching to SoTL, academics may need extra support.

Enter Educational Developers (EDs), who are well placed in any institution to assist faculty with all types of professional development (Schwartz \& Haynie, 2013) and are knowledgeable about the overarching goals and initiatives of the institution (Austin \& Sorcinelli, 2013). EDs, who in Canada typically work in Teaching and Learning Centres, can collaborate with faculty to provide encouragement to develop reflective practice and more scholarly approaches to teaching. EDs also have extensive experience managing tension, which, as GrantVallone and Ensher (2017) suggest, may be commonly felt by faculty who are "taking on new roles and duties related to service, leadership and advising" (p. 11), even though the period of MCF should be a time of relief (from achieving tenure). MCF may not believe they have the resources (time, funding, space, or support) for their endeavours to improve teaching practices, particularly when such faculty are already frustrated and disengaged (Baldwin \& Chang, 2006). Stensaker (2018) stresses that EDs are well placed to support faculty in both institutional and cultural work. 
In this paper, we summarize the common professional development challenges faced by MCF and frame our recommendations around the ways EDs can help them refocus their energies by engaging in a SoTL project. Using the micro-meso-macromega framework (Poole \& Simmons, 2013; Simmons, 2008, 2016, 2020; Williams et al., 2013; Wuetherick \& Yu, 2016), we explore support for SoTL for MCF at various levels, pointing to how SoTL can re-engage faculty towards a more energized mid-career path.

\section{Who ARE MCF?}

Mid-career is described as the time after a faculty member has obtained tenure or has been teaching in post-secondary education for more than five years and is still more than five years away from retirement (Grant-Vallone \& Ensher, 2017). In other words, this term describes the period when faculty are no longer new to the institution or teaching (Romano et al., 2004). Mid-career describes the lengthy period of time for faculty in which there are very productive periods (increased presentations and publications) combined with periods of frustration (competitive pressures, internal institutional politics, and the changing demographics of student populations) (Baldwin at al., 2008; Baker et al., 2019). This period can be both relieving and stressful at the same time. While there is a sense of relief after earning tenure, MCF often face pressures to maintain teaching vitality while balancing pressures to publish and provide student mentoring and leadership (Pastore, 2013).

MCF are often left to their own devices and can feel neglected (Baldwin et al., 2008; Karraa \& McCaslin, 2015). Due to their experience, MCF are frequently burdened with extra committee work and mentorship and pressured into taking on increased workloads to offset the workloads of newer faculty. Baldwin and Chang (2006) explain that MCF can "be either allies or stubborn opponents" (p. 28) within their institution. It is important to note that EDs have a unique opportunity to support the professional development needs of MCF.

\section{Lack of Professional Development for MCF}

As noted, there has been very little research on MCF and their professional development needs (Baldwin \& Chang, 2006; Pastore, 2013; Welch et al., 2019). Altany (2011) notes that attention for professional development is focused on earlycareer faculty in many circumstances. Perhaps there is an assumption that MCF know what they are doing in the classroom and with scholarship, along with the notion that they already "know the ropes" (Altany, 2011, p. 6) concerning best teaching practices in the classroom. However, this is not always the case. There are also increased pressures for MCF, especially around the changing demographics of student populations, external pressure from the government for performance 
measures, and pressure to remain current with content in the classroom (Pastore et al., 2019; Pastore, 2013; Welch et al., 2019). In addition, Weimer (2009) explains that it is common for MCF to experience the same routines, over and over, every semester, every year: "It's easy for teachers to find their way into comfortable routines that, before long, become deep ruts" (p. 13).

In our experience, building faculty development around the MCF cohort can be the perfect time to introduce SoTL, scholarly teaching activities, and collaborations with other MCF within the same context. As a solution to get faculty out of these so-called ruts, EDs can work directly with faculty on developing new ideas for their classrooms by engaging in SoTL work.

Baldwin and Chang (2006) created a model of the MCF development process to identify ways in which institutions can support MCF groups and their professional development. The authors recommend that all institutions need a robust program for professional development that includes collegial support (mentoring, networking, collaboration), resources (information, time, funding), and reinforcement (recognition and rewards). Their recommendations align with Pastore's (2013) conclusions that MCF need professional development at this stage in their careers, particularly to create collegial support systems and achieve their goals. The foundations created by Baldwin and Chang (2006) frame what we suggest to be the building blocks needed when assisting MCF to develop a SoTL project.

\section{Reflective Practice, SoTL, AND MCF}

Altany (2011) describes professional faculty development as a "fourth leg" in a three-legged stool (teaching, research, and service) of academic life. MCF development can be that fourth leg. Helping faculty transition into their mid-career years by focusing on professional development allows them to better understand instructional concepts and teaching processes at a deeper level. As Atlany (2011) emphasizes,

good teaching ... is an action, process, and way of thinking, and as such, it constitutes serious, complex intellectual work. It requires regular reflection and exposure to new ideas and information that are inherently a part of good professional development activities. (p. 9)

We have found that SoTL can be that source of new ideas and information.

While balancing teaching, service, research, and professional development is a reality for MCF, Huber (2001) suggests that SoTL can be used as a way to incorporate teaching and research together instead of approaching teaching, service, and research in silos. As Pinter (2019) notes, 
SoTL offers an integrating factor, especially for teaching and scholarship, which provides rich professional outlets and opportunities that extend throughout a career. For MCF in particular ... efforts to develop agency around a personal program of scholarship connected to their teaching and its integrations ... can eventually lead to presentations and publications. (p. 126)

MCF can examine their teaching practices and reflect not only on how they affect students' learning, but also where there may be room for improvement (Pastore, 2013; Strange \& Merdinger, 2015; Weimer, 2017). This reflection on teaching, the process foundational to SoTL, can be used by faculty to support improvements in teaching (Brookfield, 2006; Ferraro, 2000; Karm, 2010; Ramsden, 2003; Yost et al., 2000). It is also associated with lifelong learning (Boyer, 1990; Dewey, 1938; Herteis \& Simmons, 2010; Lyons et al., 2013; Yost et al., 2000) and can help to maintain competence in changing times (Chivers, 2003; Cranton \& King, 2003). This is true whether those changes are external (organizational change) or internal (career stage and identity shifts).

When a faculty member begins their teaching journey, they are often hired for their disciplinary expertise (Arreola et al., 2003). As they progress through the early-career-faculty stage and become more comfortable with their teaching (Simmons, 2011), they often find that teaching is a complex process and a scholarly act. Many are already primed to transition from scholarly teaching to SoTL. Richlin (2001) explains that scholarly teaching and SoTL start out on the same steps, using literature and data to inform teaching practice. Where SoTL differs is in allowing for a more formal sharing of ideas that becomes part of the higher education landscape.

We argue that SoTL is a perfect form of reflective practice to sustain faculty engagement in ongoing professional learning and reinvigorate their careers and passions. As Pinter (2019) notes, and as we have found, scholarly activity and SoTL are excellent ways for MCF to re-ignite their careers.

\section{THE 4M FRAMEWORK}

Baldwin and Chang (2006) note that mid-career professional development should take place at many levels. Campion (2015) espouses that in addition to understanding the needs and experiences of mid-career faculty, identifying the "roadblocks that hinder faculty from sustaining their intellectual vigor" is equally important (p. 14). These roadblocks can occur at many levels within higher education, including the personal and institutional level. 
We find the micro-meso-macro-mega framework (Poole \& Simmons, 2013; Simmons, 2008, 2016, 2020; Williams et al., 2013; Wuetherick \& Yu, 2016) or 4M Framework (Friberg, 2016) to be a useful heuristic when considering at what levels professional development interventions should be planned. Simmons $(2008,2016)$ describes the framework as micro (referring to the level of the individual instructor or the classroom environment), meso (the department level), macro (the institution level), and mega (the disciplinary or provincial and national levels). Numerous authors have effectively applied this particular framework to their work, explaining how SoTL can be integrated at any educational institution (DeCourcy et al., 2017; Poole \& Simmons, 2013; Simmons, 2020; Williams et al., 2013; Wuetherick \& Yu, 2016). The framework can also be used to explain the complexity of implementing SoTL in higher education (Poole \& Simmons, 2013; Kenny et al., 2017) and how EDs and others provide SoTL support at the four levels (Simmons \& Taylor, 2019).

\section{SEEING IMPACT: USING THE 4M LEVELS}

The 4M Framework also provides a guide for thinking about the benefits and impacts of MCF development throughout the organization. It allows the celebration of the individual impact and opportunities to support growing the impact when the faculty member is ready to do so.

In order to support EDs assisting MCF, we have developed some questions that EDs can ask MCF who are considering starting a SoTL project. These questions are intended to guide faculty to consider the levels at which the impact of their work might be felt. We find that faculty want to see the impact of their SoTL work, making it worth having a conversation with them about what level of impact they are seeking. For example, excellent SoTL projects might include those that improve the teaching and learning in one course; they might also be those that shift the department thinking about how courses are offered; they might also impact the overall institution by raising awareness of good teaching and learning practices.

If we are going to encourage MCF to take on additional work, it is essential to provide the encouragement to frame their efforts to have the impact they seek. Importantly, it is also worth asking yourself questions before you begin your consultations about SoTL:

- What would you recommend regarding funding/resources to get the project started?

- Would the project be focused on the micro (classroom), meso (program), or macro (institution) level?

- How will you know next year that this project was worth your effort? 


\section{Micro Level}

The main access point for SoTL is at the micro level (Chick \& Poole, 2018). While projects may expand to other levels, micro-level initiatives still emphasize possibilities for individual growth. Sometimes, the most useful aspect for MCF may be an opportunity to step back from institutional politics and re-engage with their individual core purpose for teaching. There is no reason why SoTL could not be autobiographical (self-reflective), exploring, for instance, "how I have understand my teaching at this career moment?" It might not involve collecting data from students. There are numerous journals that publish self-reflective scholarly work, such as The Canadian Journal for the Scholarship of Teaching and Learning, the Journal of the Scholarship of Teaching and Learning, and Transformative Dialogues.

SoTL could also be a way to maintain autonomy during an institutional process that is required in day-to-day MCF expectations, such as curriculum change, program evaluation, or quality assurance. EDs can help faculty seek those opportunities and count them as little wins.

\section{Meso Level}

Ultimately, micro-level engagement can lead to engagement with departments or programs, meaning that an individual SoTL project might be the starting point for some faculty members; for others, it might be joining a community of practice to talk about SoTL research possibilities. The meso level is about engaging with others at the department level and sometimes across departments as well as creating opportunities for that engagement. Individual faculty members within a department could provide mentorship for micro-level SoTL projects, or multiple faculty members within a department or program could engage in SoTL projects around curriculum renewal or pedagogical approaches. For example, Nicola recently formed an online teaching group in her program and that group is now being asked to assist in assessing online courses. The most important support at the department level is to make teaching and learning a valued part of the ongoing conversations.

These questions will set the foundation for SoTL collaborations:

- Are there teaching and learning networks within the department and/or program?

- Is there any course release available for curriculum design and revision?

- Is there a sense that teaching and learning is valued and an essential part of scholarly work? 


\section{Macro Level}

There is still much work that needs to be done to communicate how SoTL work at the individual level benefits the department and the institution more broadly (Poole \& Simmons, 2013). Advocating to have SoTL woven into institutional cultures is imperative for its success and must be coordinated across the institution, rather than depending on the isolated efforts of individuals (DeCourcy et al., 2017; Williams et al., 2013). Supporting MCF to re-engage in discussions about teaching and learning can be valuable to the institutions, and SoTL can foster positive institutional change (Poole \& Simmons, 2013).

Much of the desired support is interpersonal, occurring, for example, in significant conversations with peers (Roxå \& Mårtensson, 2009). Supporting both informal and formal mentoring, which can occasionally lead to collaborative projects, can be vital for SoTL engagement. Any opportunities to get people talking about SoTL and sharing SoTL issues and lessons learned can go a long way, whether at lunch-and-learn sessions, SoTL coffee chats, or institutional conferences. We have also both found that "just in time" learning-for example, workshops on aspects of the SoTL research process or conducting a literature review in an unfamiliar field - is always welcome.

Furthermore, while we know this already from other literature (Simmons, 2020), internal funding in the form of small SoTL grants not only provides much-needed support but also communicates that the institution values the work being done. For example, in Melanie's situation, creating an internal SoTL grant for Lethbridge College has increased the engagement of faculty participating in SoTL research. Faculty members are motivated when they perceive that their institutions value SoTL specifically and teaching and learning more broadly (Simmons, 2020; Simmons et al., in press). The following suggestions can set the foundation for SoTL collaborations at the institutional level:

- Provide opportunities for significant conversations with peers.

- Provide small grants when possible.

- Support informal/formal mentoring.

\section{Mega Level}

The literature suggests that when faculty have the opportunity to develop close relationships with colleagues, more scholarship can be produced (Strange \& Merdinger, 2014). We have mentioned institutional conferences, but finding SoTL peers often requires that faculty establish connections beyond their own institutions. Pastore et al. (2019) encourage MCF to collaborate with other MCF outside their institution. While it may be difficult for faculty to obtain funding if 
they are not presenting, there are many ways to support faculty in connecting to other SoTL scholars:

- Encourage faculty to join a SoTL group and its listserv. In Canada, these include SoTL Canada (through the Society for Teaching and Learning in Higher Education) and various regional SoTL groups. Internationally, the International Society for the Scholarship of Teaching and Learning is a crucial network.

- Suggest that faculty search online for abstracts from SoTL conferences and read SoTL journals to see what kind of work is being done. Faculty members may also offer to review for a SoTL journal.

- Invite faculty to present a poster or participate in a roundtable session in an area of teaching and learning they are curious and passionate about. Typically, in these lower-impact sessions, they can get feedback from peers on what the next steps might be. Additionally, they may find a collaborative partner for their project.

- Support faculty to write an article or shorter piece about SoTL research they have conducted or are considering. Note that peer-reviewed journal articles are not the only source of SoTL wisdom; suggest that they consider a blog or listserv post to get a conversation started.

Using the 4M Framework in MCF professional development can situate faculty in their local context, which should also align with institutional goals. For example, if a faculty member wants to focus on curriculum and program development at the meso level, then professional development related to mentoring, networking, information, time, and collaboration should be focused at that level. Most importantly, Baldwin and Chang (2006) emphasize that all initiatives for MCF growth must be carefully coordinated, systematic, and supportive. Our "BoundarySpanning Supports" image (Figure 1) illustrates numerous ways in which MCF can engage in SoTL. Notice that some initiatives occur in one of the $4 \mathrm{M}$ levels while others have the potential to be addressed in multiple 4M levels, which can help faculty who are interested in building capacity beyond their own contexts. 


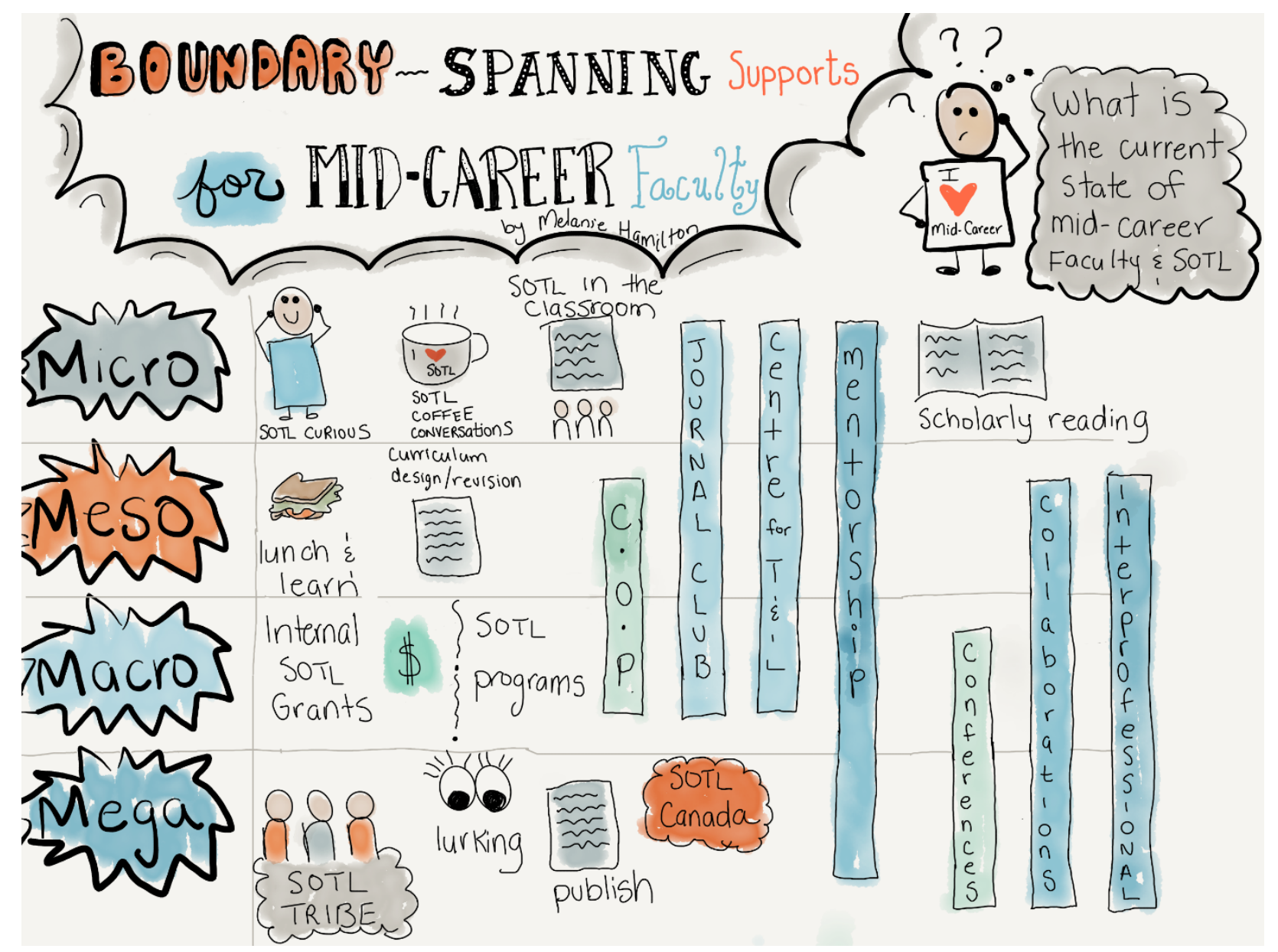

\section{M as a Developmental Path}

Some literature suggests that looking outside oneself in teaching comes after a couple of years of getting comfortable (see, for example, Simmons, 2011). MillerYoung et al. (2016) and Simmons (2016) have suggested there may be a developmental trajectory to SoTL where all work is initially micro focused. The move to considering meso, macro, and mega impact tends to come after one gets comfortable in the micro sandbox. As MCF re-engage in their own professional development, they can access support from EDs in teaching and learning centres.

We recommend that faculty purposely take time to reflect on their careers, which would allow faculty to consider their personal strengths, weaknesses, and development needs. In their mid-career faculty development model, Baldwin and Chang (2006) note that once faculty have engaged in this type of reflection, they will be better prepared to develop strategies that will align both short- and longterm goals. 


\section{BOUNDARY-SPANNING RECOMMENDATIONS}

Planning for MCF development involves a coordinated effort with MCF, senior leadership, teaching and learning centres, educational developers, and purposeful institutional support. It comprises educational development initiatives that not only touch each of the $4 \mathrm{M}$ levels but also build bridges between them.

\section{Build Peer Support}

Our single biggest recommendation from the work we have done is to create peer or group support. From an educational development perspective, sitting down with faculty one-on-one to get them through every step of the process is excellent, and faculty are very appreciative. Extra support is time-consuming, though, so it is essential to ask other beginning-level SoTL researchers to help with that support and become mentors themselves. Such support could be offered through a learning community, a SoTL book/journal club, or once-a-month informal coffee conversations. Nicola has often recommended at the end of workshops participants talk to someone and book a coffee or Skype date before they leave the room. People are motivated to do so at that moment and feedback suggests that many of those informal conversations evolve into exciting projects or ongoing peer support.

Such opportunities for networking and collaborations are significant, especially in providing peer support for faculty to engage either formally or informally with SoTL. This can be done within the institution, or it can be a virtual meeting with others outside your institution. On-site conferences, open to those both within and outside the institution that are either free or extremely affordable, allow people to meet like-minded peers without too much pressure.

Another way those who are new to SoTL can find extra support is to consider starting a SoTL project with a peer. Working with someone else, whether new to SoTL or a seasoned veteran, not only spreads out the work but creates collegiality, collaboration, and a sounding board for ideas. This could also help when disseminating ideas at a conference. Sometimes faculty express that they are nervous about presenting at a conference in front of their peers, and if they have a co-presenter, it may reduce some of the pressure and anxiety.

\section{Get Faculty Thinking About Long-term Impact}

Getting started in SoTL can feel daunting. Faculty might start as curious teachers who draw on the literature and are captivated by a question about teaching that evolves into SoTL. By spending some time reading the literature, they can increase their familiarity and level of comfort level with potential approaches and research topics. Becoming more comfortable in this way may empower them to begin a small SoTL project of their own. 
One of Nicola's early projects, which involved a small graduate class of eight participants, evolved into an exciting project with a broad impact. The original intention was to invite students to examine what was happening in one class, where they were given a lot of scope and opportunities for self-direction and course ownership. Originally, there was no intention to move beyond the micro-level, but the students wanted to write up their self-study project and present the findings at national and international conferences. Further, there has been a significant longitudinal impact: a decade later, we continue to learn from each other, still meeting for dinner a couple of times a year.

\section{Create Faculty Development Programs Specifically for MCF}

Mid-career PD programs can use both Baldwin and Chang's (2006) and Simmons' (2016) models to guide programming. One of the outcomes of professional development sessions could specifically focus on SoTL. MCF programming related to SoTL could start with discussions on:

- developing new pedagogical strategies to improve students' learning

- reflection upon their professional lives and planning for short-term and long-term goals

- the 4M Framework and how MCF can situate themselves within the levels based on their interest

- creating collaborations within and across disciplines for SoTL projects

These boundary-spanning strategies can help EDs support MCF on their SoTL development journey.

\section{Challenges}

While we have mapped some recommendations, we do not want to imply a simple process of implementation. Several potential challenges add to the complexity of any professional development, and some are specific to SoTL, as we outline below.

\section{Lack of Time and Burnout}

The mid-career person who might already be a little burned out may not be enthusiastic about taking on extra work. One approach that might be very appealing is to help them map out a time-saving SoTL project. As EDs, we need to consider what role we take on in helping faculty who are considering SoTL. It is lovely to 
ask, "where do you feel you are taking up excess time in your teaching that you wish did not take as much time?" We can then help the faculty member craft a project around that. While initially this may involve a little more work, longitudinally it can save time. One could suggest doing a SoTL project on different assessment methods that could save the faculty member marking time or exam creation time. For example, Nicola encouraged a faculty member to have their students submit exam questions as their "exit card" at the end of each lecture. Those exam questions then became the midterm and final exam.

\section{Identity Shifts}

EDs need to be aware that for faculty who are moving from a discipline unrelated to studying teaching and learning, SoTL can be a significant shift in thinking. Faculty members may experience challenges with identity and role shifts as they undertake SoTL (Simmons et al., 2013; Tsang, 2010). This is more likely to occur when they feel isolated, and learning communities can help mitigate this challenge (Simmons et al., 2013). The ISSoTL international collaborative writing group that explored these transitions notes that the more isolated people feel, the more they struggle with that shift (Simmons et al., 2013). It can help to at least know that someone else is having a similar experience.

\section{Lack of SoTL Familiarity}

In Melanie's experience, there may be an assumption that MCF are comfortable doing SoTL research. In reality, some MCF may have only completed a research project in their graduate or doctoral work. As a result, they may have minimal research background upon which to draw, while others may have done substantial disciplinary research. EDs may have to take some time to assist faculty in developing their SoTL research skills by assisting with the actual research process, including the literature review, methods and methodologies, and data analysis (Hamilton \& Benoit, forthcoming; Simmons et al., 2013).

An added complication can be that faculty will have different backgrounds regarding preparation around research methods. While some disciplines are about teaching and learning or parallel its research methods, many are not, and while faculty will have taken a research course, it may not have focused on methods pertinent to their SoTL questions (Simmons et al., 2013). For example, one of us (Nicola) had the experience of a faculty member from Economics saying, "I need a regression analysis in my paper." I suggested we talked further about that because their research question did not really point in that direction. They were concerned that their research would not be published in The Journal of Economic Education without a regression analysis. I replied, "Ok, we need to ask a different question because these are not going to match." It can be challenging to set aside 20 years of disciplinary expertise and research. Faculty may be experts in their discipline but may not have a SoTL background and might need support in entering this new 
space.

\section{Reluctant to Engage in SoTL}

Keep in mind that some people may not want to re-engage and may feel the trajectory is too much work. Engaging them in discussions about their teaching and reminding them that this is the kind of work we do can be a way of offering support. As EDs, we must keep in mind that not everyone may benefit from engaging in SoTL. Moreover, if an ED pushes too hard, some faculty may find they feel locked into a project in which they have little interest. It is critical to remember that engaging in SoTL is a choice made by the faculty member, not the ED.

\section{CONCLUSION}

As we have noted, MCF comprise the most significant demographic in higher education. MCF report that at times they feel stagnant, undervalued, and unsupported. The literature suggests that once faculty move into this long and sometimes ill-defined phase of their careers, they still need support to update their knowledge and skills, develop new teaching practices, and set new career goals.

We believe that there is still much work to be done in supporting MCF in the Canadian context. In addition to inviting others to put these ideas into practice, we recommend seeking ongoing feedback from MCF about the process and engaging them in self-study projects about their experiences. EDs can play an integral role in supporting MCF to create professional development goals. Using Baldwin and Chang's (2006) MCF development process model and Simmons' 4M Framework can be helpful ways to structure professional development; however, planned and purposeful professional development for MCF must be supported by the institution and woven into the institution's culture.

The Scholarship of Teaching and Learning is one example of what faculty may choose to develop within their short-term or long-term goals. Using the $4 \mathrm{M}$ Framework can situate the interests that faculty may have within a SoTL umbrella. The "Boundary-Spanning Supports" diagram (Figure 1) gives specific examples that EDs and MCF can use as a guide. We propose more research is needed on how to best support MCF developing a SoTL project and how EDs may assist in that process. We also recommend that institutions commit to investing in MCF through professional development programs tailored to $\mathrm{MCF}$ and specific to their unique needs. 


\section{AUTHOR BIOGRAPHY}

Melanie Hamilton, melanie.hamilton@1ethbridgecollege.ca, is an Educational Development Specialist at Lethbridge College. She is the current Chair of SoTL Canada and current Canadian VP, ISSOTL. She is also a 2020 ISSOTL Fellow. Her research interests focus on SoTL, professional development for mid-career faculty, early-career SoTL researchers, and academic integrity.

Nicola Simmons, nsimmons@,brocku.ca, is a faculty member in Educational Studies at Brock University. She is the founding Chair of SoTL Canada and a past Canadian VP, ISSOTL. Her work focuses on SoTL, online pedagogy, scholar identity and transition, and lifelong learning and meaning-making. Her teaching and research draw on arts-informed approaches. 


\section{REFERENCES}

Altany, A. (2011). Professional faculty development: A necessary fourth leg. The Teaching Professor, 25(6), 5.

Arreola, R. A., Theall, M., \& Aleamoni, L. M. (2003, April). Beyond scholarship: Recognizing the multiple roles of the professoriate [Paper presentation]. American Educational Research Association $83^{\text {rd }}$ Annual Meeting, Chicago, IL, United States.

Austin, A. E., \& Sorcinelli, M. D. (2013). The future of faculty development: Where are we going? New Directions for Teaching and Learning, 133, 85-97. https://doi.org/10.1002/tl.20048

Baker, V. L. (2019, January 30). Academe needs to take a cue from industry. Inside Higher Ed.

https://www.insidehighered.com/advice/2019/01/30/midcareer-facultymembers-need-more-training-and-development-opinion

Baker, V. L., LaPointe Terosky, A., Lunsford, L. G., Neisler, G., \& Pifer, M. J. (2019). Introduction. In V. L. Baker, L. G. Lunsford, G. Neisler, M. J. Pifer, \& A. LaPointe Terosky (Eds.), Success after tenure: Supporting mid-career faculty (pp. 1-11). Stylus.

Baldwin, R., DeZure, D., Shaw, A., \& Moretto, K. (2008). Mapping the terrain of mid-career faculty at a research university: Implications for faculty and academic leaders. Change: The Magazine of Higher Learning, 40(5), 4655, https://doi.org/10.3200/CHNG.40.5.46-55

Baldwin, R. G., \& Chang, D. A. (2006). Reinforcing our "keystone" faculty: Strategies to support faculty in the middle years of academic life. Liberal Education, 92(4), 28-35.

Boyer, E. (1990). Scholarship reconsidered: Priorities of the professoriate. The Carnegie Foundation for the Advancement of Teaching/Jossey-Bass.

Brookfield, S. D. (2006). The skillful teacher ( $2^{\text {nd }}$ ed.). Jossey-Bass.

Campion, M. A. (2015). How does a mid-career faculty development program in academic medicine impact faculty and institutional vitality? [Doctoral Dissertation, Boston University]. https://open.bu.edu/handle/2144/16037

Chick, N., \& Poole, G. (2018). Editors' introduction: In defense of microscopes. Teaching \& Learning Inquiry, 6(1), 1-2. https://doi.org/10.20343/teachlearninqu.6.1.1

Chivers, G. (2003). Utilising reflective practice interviews in professional development. Journal of European Industrial Training, 27(1), 5-15. https://doi.org/10.1108/03090590310456483

Cranton, P., \& King, K. P. (2003). Transformative learning as a professional development goal. New Directions for Adult and Continuing Education, 98, 31-37. https://doi.org/10.1002/ace.97

De Courcy, E., Loblaw, T., Paterson, J., Southam, T., \& Wilson, M. M. (2017). Framework for strengthening the scholarship of teaching and learning in the Canadian college sector. The Canadian Journal for the Scholarship of 
Teaching and Learning, 8(2), 1-20. https://doi.org/10.5206/cjsotlrcacea.2017.2.5

Dewey, J. (1938). Experience and education. Macmillan.

Ferraro, J. (2000). Reflective practice and professional development. ERIC Clearinghouse on Teaching and Teacher Education.

Friberg, J. (2016, July 11). Might the 4M framework support SoTL advocacy? The SoTL Advocate. https://illinoisstateuniversitysotl.wordpress.com/2016/07/11/might-the4m-framework-support-sotl-advocacy/

Grant-Vallone, E. J., \& Ensher, E. A. (2017). Re-crafting careers for mid-career faculty: A qualitative study. Journal of Higher Education Theory and Practice, 17(5), 10-24.

Hamilton, M. J., \& Benoit A. M. (forthcoming). Writing a SoTL research proposal: A case study of faculty experience.

Herteis, E. M., \& Simmons, N. (2010). The portfolio process: Green Guide No. 10. The Society for Teaching and Learning in Higher Education.

Hutchings, P., Huber, M. T., \& Ciccone, A. (2011). The scholarship of teaching and learning reconsidered: Institutional integration and impact. JosseyBass.

Karm, M. (2010). Reflection tasks in pedagogical training courses. International Journal for Academic Development, 15(3), 203-214. https://doi.org/10.1080/1360144X.2010.497681

Karraa, W., \& McCaslin, M. (2015). Published: A grounded theory of successful publication for midcareer scholars. The Qualitative Report, 20(8), 13321358.

Kenny, N., Popovic, C., McSweeney, J., Knorr, K., Hoessler, C., Hall, S., Fujita, N., \& El Khoury, E. (2017). Drawing on the principles of SoTL to illuminate a path forward for the scholarship of educational development. The Canadian Journal for the Scholarship of Teaching and Learning, 8(2), 1-19. https://doi.org/10.5206/cjsotl-rcacea.2017.2.10

Lyons, N., Halton, C., \& Freidus, H. (2013). Reflective inquiry as transformative self-study for professional education and learning. Studying Teacher Education, 9(2), 163-174. https://doi.org/10.1080/17425964.2013.808057

Miller-Young, J., Yeo, M., Manarin, K., Carey, M., \& Zimmer, J. (2016). SoTL 2 : Inquiring into the impact of inquiry. New Directions for Teaching and Learning, 146, 55-62. https://doi.org/10.1002/t1.20187

Pastore, D. L., Dahlin, S., \& Morton, J. (2019). Mid-career faculty development model: Sport management faculty perspectives. The Physical Educator, 76, 1102-1127. https://doi.org/10.18666/TPE-2019-V76-I4-8874

Pastore, D. L. (2013). Faculty perspectives on Baldwin and Chang's mid-career faculty development model. Journal of Faculty Development, 27(2), 2532.

Pinter, M. (2019). Scholarship of teaching and learning as a vehicle for thriving in mid-career. In V. L. Baker, L. G. Lunsford, G. Neisler, M. G. Pifer, \& A. LaPointe-Terosky (Eds.), Success after tenure: Supporting mid-career 
faculty (pp. 123-141). Stylus.

Poole, G., \& Simmons, N. (2013). Contributions of the scholarship of teaching and learning to quality enhancement in Canada. In R. Land \& G. Gordon (Eds.), Enhancing quality in higher education: International perspectives (pp. 118-128). Routledge.

Ramsden, P. (2003). Learning to teach in higher education ( $2^{\text {nd }}$ ed.). RoutledgeFalmer.

Richlin, L. (2001). Scholarly teaching and the scholarship of teaching. New Directions for Teaching and Learning, 2001(86), 57-68. https://doi.org/10.1002/t1.16

Romano, J. L., Hoesing, R., O’Donovan, K., \& Weinsheimer, J. (2004). Faculty at mid-career: A program to enhance teaching and learning. Innovative Higher Education, 29(1), 21-48. https://doi.org/10.1023/B:IHIE.0000035365.92454.a5

Ross, C. (2015). Teaching renewal for midcareer faculty: Attending to the whole person. To Improve the Academy: A Journal of Educational Development, 34(1-2), 270-289. https://doi.org/10.1002/tia2.20023

Roxå, T., \& Mårtensson, K. (2009). Significant conversations and significant networks - Exploring the backstage of the teaching arena. Studies in Higher Education, 34(5), 547-559. https://doi.org/10.1080/03075070802597200

Schwartz, B. M., \& Haynie, A. (2013). Faculty development centers and the role of SoTL. New Directions for Teaching and Learning, 136, 101-111. https://doi.org/10.1002/t1.20079

Simmons, N. (2008, October). Navigating institutional SoTL cultures: Faculty developers as conversation catalysts [Paper presentation]. International Society for the Scholarship of Teaching and Learning Conference, Edmonton, AB, Canada.

Simmons, N. (2011). Caught with their constructs down? Teaching development in the pre-tenure years. International Journal for Academic Development, 16(3), 229-241. https://doi.org/10.1080/1360144X.2011.596706

Simmons, N. (2016). Synthesizing SoTL institutional initiatives toward national impact. New Directions for Teaching and Learning, 2016(146), 95-102. https://doi.org/10.1002/t1.20192

Simmons, N. (2020, in press). The 4M Framework as analytic lens for SoTL's impact. Teaching and Learning Inquiry.

Simmons, N., Abrahamson, E., Deschler, J. M., Kensington-Miller, B., Manarin, K. Morón-García, S., Oliver, C., \& Renc-Roe, J. (2013). Conflicts and configurations in a liminal space: SoTL scholars' identity development. Teaching and Learning Inquiry, 1(2), 9-21. https://doi.org/10.20343/teachlearninqu.1.2.9

Simmons, N., Eady, M., Gregory, D., \& Scharff, L. (in press). SoTL in the margins: Teaching-stream role case studies. Teaching and Learning Inquiry.

Simmons, N., \& Taylor, K. L. (2019). Leadership for the Scholarship of Teaching 
and Learning: Understanding bridges and gaps in practice. The Canadian

Journal for the Scholarship of Teaching and Learning, 10(1). https://doi.org/10.5206/cjsotl-rcacea.2019.1.7995

Smith, J. E. (2017). Faculty members' perceptions of their scholarship of teaching and learning: A qualitative study [Doctoral dissertation, Indiana University of Pennsylvania]. ProQuest LLC.

Stensaker, B. (2018). Academic development as cultural work: Responding to the organizational complexity of modern higher educational institutions. International Journal for Academic Development, 23(4), 274-285. https://doi.org/10.1080/1360144X.2017.1366322

Strange, A., \& Merdinger, J. (2014). Professional growth and renewal for midcareer faculty. Journal of Faculty Development, 28(3), 41-50.

Tsang, A. (2010). Pitfalls to avoid in establishing a SoTL academic pathway: An early career perspective. International Journal for the Scholarship of Teaching and Learning, 4(2). https://.org/10.20429/ijsotl.2010.040219

Weimer, M. (2009). Those long years in doi the middle. Faculty Focus, 23(2), 3.

Weimer, M. (2017). Mid-career faculty: 5 great things about those long years in the middle. Faculty Focus. https://www.facultyfocus.com/articles/facultydevelopment/mid-career-faculty-five-great-things/

Welch, A. G., Bolin, J., Reardon, D., \& Stenger, R. (2019). Mid-career faculty: Trends, barriers, and possibilities. Journal of the Professoriate, 10(1), 2242.

Williams, A. L., Verwoord, R., Beery, T. A., Dalton, H., McKinnon, J., Strickland, K., Pace, J., \& Poole, G. (2013). The power of social networks: A model for weaving the scholarship of teaching and learning into institutional culture. Teaching and Learning Inquiry, 1(2), 49-62. https://doi.org/10.2979/teachlearninqu.1.2.49

Wilson, R. (2012). Why are associate professors so unhappy? The Chronicle of Higher Education. https://www.chronicle.com/article/why-are-associateprofessors-so-unhappy/

Wuetherick, B., \& Yu, S. (2016). The Canadian teaching commons: The scholarship of teaching and learning in Canadian higher education. New Directions for Teaching and Learning, 146, 23-30. https://doi.org/10.1002/t1.20183

Yost, D. S., Sentner, S. M., \& Forlenza-Bailey, A. (2000). An examination of the construct of critical reflection: Implications for teacher education programming in the $21^{\text {st }}$ century. Journal of Teacher Education, 51(1), $39-49$. 